\title{
Innovation Credit: When Can Leaders Oppose Their Group's Norms?
}

\author{
Dominic Abrams and Georgina Randsley de Moura \\ University of Kent
}

\author{
José M. Marques \\ University of Porto
}

\author{
Paul Hutchison \\ London Metropolitan University
}

\begin{abstract}
Two preliminary studies and 5 experiments examined judgments of leaders who challenge their group's norms. Participants viewed information about group members whose attitudes were normative or deviated in a pronormative or antinormative direction. The antinorm member was identified as (a) either a nonleader or an established leader (Study 1), (b) an ex-leader (Studies 2 and 5), or (c) a future leader (Studies 3, 4, and 5). Antinorm future leaders were judged more positively and were granted greater innovation credit (license to innovate and remuneration) relative to antinorm members, ex-leaders, and established leaders. Results are discussed in terms of the idea that leadership can accrue from prototypicality and can also confer the right to define prescriptive norms. However, innovation credit is only granted in the case of future leaders.
\end{abstract}

Keywords: leadership, deviance, prototypicality, innovation, subjective group dynamics

A challenge for many leaders in organizations is to drive organizational change and take the group in new directions (cf. Coser, 1962; Homans, 1974). In addition, leaders such as those representing unions or management sometimes have to resist the more extreme demands of the group they represent to negotiate settlements (Stephenson, 1991). Political leaders, such as Gerry Adams and David Trimble in Northern Ireland, regularly have to reach an agreement by shifting toward acceptance of a position preferred by their opposite number's group. Such acts of independence may put the leader's position at risk and result in the leader being deselected or eliminated from the group. David Trimble, despite having won the Nobel Peace Prize, lost his position as leader of the Ulster Unionists.

Hollander (1958; Hollander \& Julian, 1970) outlined the conditions that should enable leaders to deviate from prevailing group norms. The idiosyncrasy credit model conceptualized leadership in terms of relations with followers and proposed that leaders gain trust from their followers on the basis of their performance over time and from positive contributions to the group. Once sufficient

Dominic Abrams and Georgina Randsley de Moura, Centre for the Study of Group Processes, Department of Psychology, University of Kent, Canterbury, England; José M. Marques, Faculdade de Psicologia e de Ciências da Educação, University of Porto, Porto, Portugal; Paul Hutchison, Department of Psychology, London Metropolitan University, London, England.

This research was supported in part by Grants R42200034207 and R42200024342 from the Economic and Social Research Council. We are grateful to Barbara Masser for suggesting the term innovation credit after reading an earlier version of this article and to Jack Dovidio, John Levine, Norbert Kerr, Katerina Tasiopoulou, and Tim Hopthrow for comments.

Correspondence concerning this article should be addressed to Dominic Abrams or Georgina Randsley de Moura, Centre for the Study of Group Processes, Department of Psychology, University of Kent, Canterbury CT2 7NP, England. E-mail: D.Abrams@kent.ac.uk or G.R.de-Moura@kent.ac.uk idiosyncrasy credits had been accumulated by being loyal to the group, the leader should be permitted to introduce innovation and changes. However, it is unclear whether there may be some conditions, independent of the leader's actions or performance but attributable merely to the leader's relationship to other members, that might affect the generosity or punitiveness with which leaders are treated by other members.

This article examines what happens when a leader resists the mode of opinion within a group, leaning instead toward that of an outgroup (antinorm deviance). We use the subjective group dynamics (SGD) framework (Marques, Páez, \& Abrams, 1998) to investigate how group members respond to antinormative leaders and whether responses depend on the phase of the leader's role. We contend that people use two distinct criteria for evaluating leaders: The accrual criterion is based on the leader's demonstrable adherence to the group prototype, and the conferral criterion is based on the inference that mere occupancy of the leadership role accords greater latitude to determine the prescriptive norm of the group. We also contend that the phase of leadership (ex, current, future) will affect the weight members attach to the accrual and conferral criteria. We examine how phase of leadership affects the way antinorm leaders are perceived, evaluated, given license to innovate, and rewarded.

\section{Social Identity, SGD, and Deviance}

According to social identity theory (Tajfel \& Turner, 1979) and self-categorization theory (Turner, Hogg, Oakes, Reicher, \& Wetherell, 1987), people's positive identity as a group member depends on intergroup comparisons. A metacontrast between these intergroup and intragroup differences defines the positions (e.g., attitudes or actions) that are perceived to be relatively prototypical for the ingroup and the outgroup. These prototypes ultimately provide a basis for depersonalized attraction among group members (Hogg, 2001a; Turner et al., 1987). 
Although self-categorization theory argues that group differences are organized in terms of differing prototypes, it is often the case that group members who denotatively are unquestionably members of a particular group (e.g., male) deviate from the prescriptive norms of that group (e.g., to be masculine; Abrams, Marques, Bown, \& Henson, 2000; Abrams, Marques, Randsley de Moura, Hutchison, \& Bown, 2004; Marques, Páez, \& Abrams, 1998). Thus, although prototypical positions are often prescriptively normative, it is not always the case that prescriptively normative positions have to be prototypical, as illustrated by phenomena such as pluralistic ignorance and social projection (e.g., Prentice \& Miller, 1993).

The SGD model (e.g., Abrams, Randsley de Moura, Hutchison, \& Viki, 2005; Marques, Páez, \& Abrams, 1998; Marques \& Páez, 1994) proposes that group members use intragroup differentiation for a further purpose-not just to judge the group prototypes but also to reinforce prescriptive ingroup norms. Research shows that subjective dynamics, or norm-reinforcement processes, begin to operate from quite an early age and may form part of the unwritten conventions of group membership (Abrams \& Rutland, 2008; Abrams, Rutland, \& Cameron, 2003). Evidence across a wide range of group memberships shows that members expect one another, and are motivated, to validate ingroup norms (Abrams, Marques, Randsley de Moura, Hutchison, \& Bown, 2004; Abrams et al., 2005; Abrams, Rutland, Cameron, \& Ferrell, 2007; Abrams, Rutland, Ferrell, \& Pelletier, in press). Reinforcement of these norms is often achieved by derogating ingroup members who deviate from their own group's norms. People may also upgrade antinorm outgroup members if the latter deviate toward ingroup norms, resulting in a "black sheep" effect (Marques, Abrams, Páez, \& Taboada, 1998; Marques, Páez, \& Abrams, 1998; Marques, Yzerbyt, \& Leyens, 1988).

Abrams et al. (2000, Study 2) informed participants about the different norms of their ingroup (psychologists) and an outgroup (customs officers). Participants then learned about a set of group members that included normative, pronorm deviant, and antinorm deviant targets. Pronorm deviants diverged from the opposing group's norm to an extent that was well beyond their own group norm. Thus, they did not challenge the prototype of their group relative to that of the outgroup and were consistent with both denotative and prescriptive differences between groups (see also Abrams, Marques, Bown, \& Dougill, 2002; Abrams et al., 2004, 2005). Antinorm deviants expressed attitudes that diverged toward the opposing group's norm. Indeed, the antinorm deviants from the ingroup and outgroup expressed identical attitudinal positions, midway between both group norms.

Participants' assessments of the typicality of members compressed differences between normative and pronorm members (also see Abrams et al., 2002). Additional evidence suggests that under some circumstances, extremist pronorm members may even be judged as more representative of the group than moderate members (Haslam, Oakes, McGarty, Turner, \& Onorato, 1995). In contrast, antinorm deviants are generally viewed as highly atypical.

According to the SGD model, antinorm deviants potentially challenge or undermine the validity of the prescriptive norm. Consequently, reinforcement of group norms is much more dependent on reactions to antinorm than to pronorm deviants. Abrams et al. (2000) found that ingroup antinorm deviants were evaluated less favorably than other ingroup members and than an outgroup antinorm deviant who expressed the same attitudes. These results were consistent with the idea that participants are especially sensitive to antinorm deviance, and their responses reinforce the ingroup's prescriptive norm.

Abrams et al.'s (2000) paradigm is useful because it depicts group members in a quasinormal distribution, wherein the presence of the pronorm and antinorm deviants seems plausible. Given that participants are likely to make distinctive responses to antinorm members, the paradigm allows us to evaluate the impact of other factors on those judgments. The present series of studies vary the leadership status of the antinorm targets within this paradigm.

\section{Leadership}

The social identity perspective on leadership (e.g., Haslam, 2001; Hogg, 2001c; Hogg \& van Knippenberg, 2003; Turner \& Haslam, 2001) proposes that a central aspect of leadership is the extent to which the leader can embody the group prototype. Group leaders are likely to be individuals who best represent the group's identity and who best reflect the group's consensual or prototypical position (Haslam, 2001; Reicher, Haslam, \& Hopkins, 2005; Turner, 1991; van Knippenberg \& van Knippenberg, 2005). Previous research investigating leadership from a social identity perspective shows that more prototypical leaders are generally evaluated more positively (e.g., Hains, Hogg, \& Duck, 1997; Haslam \& Platow, 2001; Haslam et al., 2001; Hogg, Hains, \& Mason, 1998; Hogg \& van Knippenberg, 2003; Platow \& van Knippenberg, 2001). However, previous studies have not attended closely to the question of whether this advantage results from prototypicality per se or from occupancy of the leader role in combination with prototypicality. Specifically, there has not been a systematic comparison of leaders versus nonleaders who share the same levels of prototypicality. For example, in the studies conducted by Haslam, Platow, and colleagues (e.g., Haslam \& Platow, 2001; Platow \& van Knippenberg, 2001; Platow, van Knippenberg, Haslam, van Knippenberg, \& Spears, 2006), the only targets were already labeled as leaders. No comparable nonleaders were presented.

There could be a variety of reasons why evaluations of nonprototypical targets might differ depending on their role, as we discuss below. Therefore, one important contribution of the present research is to disambiguate whether there is anything distinctive about the effects of deviance for the leadership role.

Fielding and Hogg (1997, p. 41) proposed that,

More prototypical group members are more likely both to become leaders and to be perceived as effective leaders. . .The longer specific individuals remain in a leadership position. . .[the more they]. . .are able to exercise the more active aspects of leadership, including the power to be innovative and constructively deviant.

We propose that it is useful to decompose these ideas into two distinct components-accrual and conferral.

\section{Accrual and Expectancy Violation}

The social identity analysis of leadership focuses to a large extent on the process by which members accrue the status of leader (e.g., Haslam, 2001; Haslam \& Platow, 2001; Hogg, 2001b, 2001c; 
Hogg \& van Knippenberg, 2003; Platow \& van Knippenberg, 2001; Reicher et al., 2005). This work, and, more specifically, Hogg's (2001c; Hogg \& van Knippenberg, 2003) social identity theory of leadership, is consistent with the idea that leadership accrues from prototypicality. For example, in a study examining the selection of leaders, Hogg et al. (1998) found that those chosen as leaders were considered to be significantly more group prototypical than other group members. It follows that less prototypical group members fit the role of leader less well in the eyes of other group members and thus should be less likely to emerge as a leader.

These ideas are echoed by Reicher and Hopkins (2003), who suggested that leaders must work to ensure their prototypicality as a means of securing their position and influence. This suggests that antinorm leaders will not be prototypical and will, therefore, be deprived of the aura of charisma often associated with the leader (e.g., Platow et al., 2006). Ingroup antinorm deviant members are generally evaluated more negatively than other members. Is the same true of leaders who wish to take their groups in new, perhaps counternormative, directions? It remains unclear from previous leadership research whether antinorm leaders are perceived and treated as less or more typical of the group than antinorm nonleaders.

The accrual process should predict simply that antinorm members, by virtue of being nonprototypical, should not be leaders and should not be evaluated positively by other members. The process does not distinguish between leaders and nonleaders. If accrual operates, then an antinorm leader should be judged similarly to an antinorm member because both are nonprototypical and hence should be ineligible for (or illegitimate occupants of) the leadership role.

We propose two caveats to the accrual process. Previous research suggests that one reason for negative reactions to antinorm deviants is that they violate expectancies (Biernat, Vescio, \& Billings, 1999). If prototypical members are usually regarded as appropriate leaders because of accrual, then people should be surprised if a leader turns out to be antinormative. Thus, an antinorm leader should be judged as more atypical than an antinorm member, and evaluations of an antinorm leader may be more negative because of the unexpected violation of leadership stereotype (cf. Lord \& Maher, 1990).

The SGD model would also concur with the expectancy violation prediction for an ingroup leader, but for different reasons. If an ingroup leader violates a prescriptive norm, then this may be more threatening and should invite more negative reactions than if a nonleader member does so (Marques, Abrams, \& Serodio, 2001). Moreover, the SGD model makes reverse predictions for an outgroup leader. An antinorm outgroup leader should be evaluated more positively because of the additional validation that would be derived for ingroup norms.

\section{Conferral}

The second element of Fielding and Hogg's (1997) reasoning is that because a leader has acquired the status and power of the leadership role (albeit by virtue of being prototypical), the leader has permission to deviate. Some evidence does suggest that, other things being equal, the leadership role may confer the potential to define the prescriptive norm.
Conferral might plausibly occur for several reasons. Leaders may be assumed to have expertise, which would give them more legitimacy as opinion leaders. Leaders might be assumed to have higher than typical commitment to the group. In addition, members may not always have sufficient information to fully evaluate a leader's prototypicality. Hence, people may use the mere occupancy of the leader role as a heuristic for assuming the leader is likely to represent the prescriptive norm. This heuristic may be especially important if there is no opportunity for direct interaction or communication between the leader and members. In this situation, members must use simple categorical information (e.g., the leader's role) as a guide for judgment. Consistent with these ideas, Hogg (2001b) proposed that some of the qualities that are stereotypical of leaders in general (cf. Lord \& Hall, 2003) may be attributed to people who hold leadership status a result of the fundamental attribution error or correspondence bias (Gilbert \& Malone, 1995; Ross, 1977). If this conferral process occurs, then we would expect antinorm leaders to be evaluated more positively than antinorm members.

\section{Phase of Leadership}

The accrual and conferral processes seem potentially contradictory-if conferral allows a previously prototypical leader room to deviate, then he or she is no longer prototypical and thus fails the eligibility test according to the accrual criterion. However, implicit in Fielding and Hogg's (1997) reasoning is the idea that the role of prototypicality may vary as a function of time. Levine and Moreland (1994) have highlighted the importance of considering group dynamics from a temporal perspective. Consistent with the idea that there are distinct phases, organizations sometimes formally define leader occupancy through titles such as President Elect, President, and Vice President (the British Psychological Society being one example). Thus, it seems reasonable to suppose that ex-leadership and future leadership have meanings that differ from current leadership and from ordinary membership. Indeed, we contend that leaders may also face different criteria for evaluations depending on the phase of their occupancy of the role (Abrams et al., 2005; Randsley de Moura \& Abrams, 2002).

It is not uncommon for ex- and prospective leaders to offer opinions or advice that may contradict current group norms (e.g., over political policy or organizational strategy). However, it could be assumed that these opinions have different implications at different phases of leadership. For example, ex-leaders may have lost their position because of lack of support or simply because their term of office ended. Ex-leaders may have minimal power or authority over the group and thus may not receive the attention or concern that current or future leaders do. Assuming current leaders wish to hold on to power, members may feel they have some leverage over those leaders and can hold them accountable. In contrast, future leaders generally have a guaranteed position and power. Members may be reluctant to challenge, and may feel obliged to accept, the agendas that new leaders want to set. One part of leading, after all, is innovating (Yukl, 2002; Hogg, 2005).

In the case of past and current leaders, prescriptiveness seems likely to remain constantly under review. We expect that past and current antinorm leaders are likely to be scrutinized and evaluated negatively because they fail the prototypicality criterion required for accrual. Indeed, they break expectations of loyalty (Zdaniuk \& 
Levine, 2001), and, because this might be particularly problematic for a current leader, they may be judged at least as harshly as, if not more than, a comparable antinorm nonleader.

We expect that the conferral criterion will come into play for future leaders. Future leaders should be able to benefit from the conferral process, in which members assume the leader embodies prescriptive norms despite any divergence from the prototype that could be inferred from information about other members.

We recognize that there may be many variables that could affect accrual and conferral. However, the goal in the present research is to see whether, all else being equal, phase of leadership can affect the likelihood of these two processes occurring. To test these ideas, it is necessary to examine judgments of leaders with whom participants do not have a prior history (i.e., for whom there is no prior evidence regarding prototypicality) or a personal relationship and whose objective level of prototypicality is controlled precisely. In addition, it is essential to know how evaluations of antinorm leaders compare with evaluations of antinorm nonleaders. If accrual operates, evaluations should be more responsive to the target's adherence to prescriptive norms than to the leadership role. If conferral operates, evaluations should be relatively more responsive to the leadership role.

\section{Preliminary Research}

Our reasoning implies that normative members should more readily be seen as viable leaders (accrual) and that leaders can also be given license to innovate (conferral). Indeed, Fielding and Hogg (1997, p. 41) suggested,

leaders should adhere to group norms (e.g., Hollander, 1958) and be representative group members (e.g., Eagly, Karau, \& Makhijani, 1995; Eagly, Makhijani, \& Klonsky, 1992) but that they should also be innovative and thus "deviant" from the group (e.g., Bray, Johnson, \& Chilstrom, 1982; Hollander, 1958; see Levine, 1989).

To support these ideas empirically, we need to show that people perceive both normativeness and distinctiveness as positive aspects of leadership.

Two hundred eighty-six introductory psychology students (55 male) indicated their level of agreement $(1=$ strongly disagree, 7 = strongly agree) with four items as part of a mass testing session. Two items tapped leader normativeness: “A good leader's attitudes and values should match those of his or her own group as closely as possible," and "A good leader should be completely representative of their group." Two items tapped leader distinctiveness: "Really good leaders stand out from the group and have a distinct agenda," and "In a group the best leaders always emerge as a bit distinct from the others."

Factor analysis of the four items revealed two factors with no cross-loading and a small but positive correlation $(r=.22)$. We formed composites of the two measures. Both normativeness and distinctiveness were considered important features of leadership, as both were significantly different from the midpoint of the scale: normativeness, $t(285)=22.54, p<.001, d=2.67$; distinctiveness, $t(285)=17.00, p<.001, d=2.01$. Consistent with Hogg's (2001b) approach to leadership, normativeness came out significantly higher $(M=5.33, S D=0.99)$ than distinctiveness $(M=$ $5.01, S D=1.00), t(285)=4.31, p<.001, d=0.51$. This is what we would expect for current leaders, which is what the items implicitly assess. These findings demonstrate that people perceive normativeness and distinctiveness as two separable components of leadership. Furthermore, they show that both attributes are perceived as important.

The second assumption to address in our research is that future leaders are seen as more able to dissent. During a separate experiment (not about leadership), we asked participants about either new $(n=20)$ or ex- $(n=21)$ leaders. We simply asked them whether "New [Ex] leaders of groups should feel free to disagree with the group's past positions." As expected, participants agreed with the item significantly more in the case of new leaders $(M=$ $6.05, S D=0.69)$ than in the case of ex-leaders $(M=5.29, S D=$ $1.23), t(39)=2.47, p=.02, d=0.79$. This shows that distinctiveness is seen as more acceptable for new leaders.

These findings support our contention that people do see normativeness and distinctiveness as positive components of leadership and that people believe new leaders should be able to innovate more than ex-leaders. Although these two sources of evidence are preliminary, they are consistent with our conceptualization that phase should be relevant for judgments of leaders.

\section{Analytic Strategy}

For each of the studies that follow, we first examined our assumptions that the context was relevant and that the targets could be clearly distinguished. On the basis of Abrams et al.'s (2000) work, the first check examined whether, prior to judging targets, participants would endorse the ingroup more than the outgroup. The means and significance tests for ingroup-outgroup differences in each study are presented in Table 1 . In all studies, participants significantly favored the ingroup over the outgroup.

The second check was to establish that participants perceived differences between the policy positions advocated by different types of targets (antinorm, normative, pronorm). Analyses of variance (ANOVAs) on these judgments should be significant and reveal pairwise differences between targets. In all studies, these differences were significant (see Table 2).

We also compared the policy check data for ingroup targets across Studies 1-5 to ensure that the normative context remained the same across studies. A Target (pronorm, norm, antinorm) $\times$ Study $(1,2,3,4,5)$ mixed ANOVA revealed a significant effect of target, $F(2,414)=740.40, p<.001, \eta^{2}=.81$, and no significant effect of study or the Target $\times$ Study interaction $\left(F_{\mathrm{s}}<1.00, p \mathrm{~s}>\right.$ .62 ). Thus, the mean position adopted by targets and the differences between them were judged similarly across studies. The pronorm deviant was perceived as having the most open policy

Table 1

Mean (and Standard Deviation) for Global Group Evaluations Across Studies

\begin{tabular}{cccc}
\hline Study & Ingroup & Outgroup & ANOVA statistic \\
\hline 1 & $5.33(0.89)$ & $3.68(1.30)$ & $F(1,51)=65.60, p<.001, \eta^{2}=.56$ \\
2 & $5.10(0.70)$ & $4.19(1.25)$ & $F(1,40)=22.46, p<.001, \eta^{2}=.36$ \\
3 & $5.00(0.82)$ & $3.85(1.19)$ & $F(1,44)=29.12, p<.001, \eta^{2}=.40$ \\
4 & $5.07(0.70)$ & $3.77(1.04)$ & $F(1,41)=40.31, p<.001, \eta^{2}=.50$ \\
5 & $5.23(1.00)$ & $4.08(1.40)$ & $F(1,49)=29.36, p<.001, \eta^{2}=.38$ \\
\hline
\end{tabular}

Note. $\quad$ ANOVA $=$ analysis of variance. 
Table 2

Mean (and Standard Deviation) for Dependent Measures for Each Level of Target Across Studies

\begin{tabular}{|c|c|c|c|c|}
\hline Study and level & Pronorm & Norm & Antinorm & ANOVA statistic \\
\hline \multicolumn{5}{|l|}{ Study 1: Ingroup } \\
\hline Policy & $2.30(0.91)$ & $4.06(0.38)$ & $5.85(0.86)$ & $F(2,48)=76.53, p<.001, \eta^{2}=.76$ \\
\hline Typicality & $3.96(1.43)$ & $4.72(0.96)$ & $3.77(1.73)$ & $F(2,47)=9.98, p<.001, \eta^{2}=.30$ \\
\hline Favorability & $5.04(1.40)$ & $4.31(1.02)$ & $2.78(1.40)$ & $F(2,48)=19.13, p<.001, \eta^{2}=.44$ \\
\hline \multicolumn{5}{|l|}{ Study 1: Outgroup } \\
\hline Policy & $6.73(0.67)$ & $5.42(0.83)$ & $4.88(0.99)$ & $F(2,48)=25.40, p<.001, \eta^{2}=.51$ \\
\hline Typicality & $5.92(1.29)$ & $5.20(0.89)$ & $4.35(1.60)$ & $F(2,47)=4.14, p=.02, \eta^{2}=.15$ \\
\hline Favorability & $2.46(1.42)$ & $3.44(1.16)$ & $4.08(1.47)$ & $F(2,48)=7.55, p=.001, \eta^{2}=.24$ \\
\hline \multicolumn{5}{|l|}{ Study 2} \\
\hline Policy & $2.36(0.96)$ & $3.95(0.78)$ & $5.60(1.13)$ & $F(2,80)=168.55, p<.001, \eta^{2}=.81$ \\
\hline Typicality & $4.21(1.32)$ & $4.61(0.90)$ & $3.71(1.50)$ & $F(2,80)=5.41, p=.006, \eta^{2}=.12$ \\
\hline Favorability & $4.19(1.70)$ & $4.21(0.93)$ & $3.55(1.58)$ & $F(2,80)=2.57, p=.049, \eta^{2}=.06$ \\
\hline \multicolumn{5}{|l|}{ Study 3} \\
\hline Policy & $2.42(0.81)$ & $3.99(0.46)$ & $5.69(0.85)$ & $F(2,86)=196.14, p<.001, \eta^{2}=.82$ \\
\hline Typicality & $4.22(1.13)$ & $4.22(0.87)$ & $3.67(1.15)$ & $F(2,86)=3.60, p=.032, \eta^{2}=.08$ \\
\hline Favorability & $4.20(1.50)$ & $4.18(0.94)$ & $3.52(1.43)$ & $F(2,88)=3.94, p=.023, \eta^{2}=.08$ \\
\hline \multicolumn{5}{|l|}{ Study 4} \\
\hline Policy & $2.58(1.05)$ & $3.93(0.56)$ & $5.51(1.03)$ & $F(2,82)=95.34, p<.001, \eta^{2}=.70$ \\
\hline Typicality & $4.19(0.99)$ & $4.54(0.90)$ & $3.36(1.16)$ & $F(2,80)=14.12, p<.001, \eta^{2}=.26$ \\
\hline Favorability & $4.19(1.33)$ & $4.26(0.86)$ & $3.62(1.45)$ & $F(2,80)=3.24, p=.04, \eta^{2}=.08$ \\
\hline Study 5: Policy & $2.61(0.97)$ & $4.09(0.56)$ & $5.64(0.88)$ & $F(2,106)=205.53, p<.001, \eta^{2}=.80$ \\
\hline
\end{tabular}

Note. In all studies, judgments of normative members (Persons A, C, D, and F) were averaged and used as an index for the normative targets. These indexes were reliable in all studies $(\alpha \mathrm{s}<.80)$. For the policy orientation measure, means for all targets differed significantly using Bonferroni adjustment. For other measures, the antinorm target was always significantly different from other targets. The full analyses of variance (ANOVAs) with target as a within-participants factor were included in an earlier version of this article and are available on request from the authors.

position $(M=2.46, S D=0.93)$, followed by the normative targets, who supported the status quo $(M=4.01, S D=0.57)$, followed by the antinorm deviant, who was judged to hold the most closed policy position $(M=5.66, S D=0.94 ; p \mathrm{~s}<.001$ for all comparisons with Bonferroni adjustment). Meta-analytically, the mean effect size for target was mean $r=.80, Z=20.32, p=$ $2.80 \mathrm{E}-45$. The chi square $(d f=4)$ for the diffuse comparison of effect sizes was $3.67(p=.45)$, showing that the effect sizes did not differ significantly across studies. These results indicate that the data across studies are comparable and that despite differences in date of testing, participants viewed the target positions in the same way.

For the dependent variables, we initially conducted Condition $X$ Target ANOVAs. In Study 1, we present the results using this design to check for the black sheep effect, which predicts an interaction between group (ingroup vs. outgroup) and target (antinorm vs. others). Studies 2-5 only concern ingroup targets, and our hypotheses concern effects of condition on reactions to antinorm targets. For this reason, and for economy of presentation, we report results for judgments of antinorm targets while covarying out judgments of the normative and pronorm targets. Significant effect sizes of condition on antinorm targets (on which the manipulations of leadership are focused) are identical to those obtained using the full mixed design, which yield significant Condition $\times$ Target interactions. In addition, we present the means and $F$ values for differences among targets in Table 2.

\section{Overview and Hypotheses}

Our five studies closely follow the method used by Abrams et al. (2000, Study 2). If leadership is normatively accrued, then an ingroup antinorm deviant will be judged as highly atypical and will be judged less favorably than other members (accrual hypothesis). Given that people may expect leaders to be more prototypical than other members, observing an antinorm leader should be a larger expectancy violation than observing an antinorm member. Consequently, reactions to antinorm leaders should be more negative than reactions to antinorm members (expectancy violation hypothesis). Finally, if leadership confers prescriptive normativeness, then an ingroup antinorm leader should be judged as less deviant and should be evaluated more favorably than a comparable nonleader (conferral hypothesis). Study 1 examines responses to ingroup and outgroup antinorm targets who are defined either as a member or as the established group leader. Study 2 examines responses when ingroup antinorm targets are members or are designated as the ex-leader. Study 3 examines the case of a future leader. Study 4 also investigates the case of future leaders and whether judgments of the antinorm leader may be a function of the salience of the antinorm member. Finally, Study 5 examines how past and future antinorm leaders compare with nonleaders in terms of their capacity to innovate and the rewards they are deemed to deserve.

\section{Study 1: Established Leader}

Our primary question in Study 1 is whether being an antinorm leader has different effects from merely being an antinorm member. The second question is whether evaluations of antinorm leaders depend on the leader's group membership. In the studies by Haslam, Platow, and colleagues, the leaders were always in the participants' ingroup (Haslam \& Platow, 2001; Platow \& van Knippenberg, 2001). However, it also possible that an outgroup antinorm leader may, by adopting the middle ground between groups, become more appealing to members of the ingroup and 
thus contribute to the subjective validity of the ingroup's position by broadening the consensual basis for their support (cf. Abrams et al., 2000, 2005; Giddens, 2000; Major, 2000). Thus, Study 1 tests whether judgments of antinorm leaders are driven primarily by ingroup prescriptive normativeness (accrual, replicating Abrams et al., 2000) or conferral, which would result in more positive evaluations of the ingroup antinorm leader but more negative evaluations of the outgroup antinorm leader.

Study 1 uses the 2 (group: ingroup vs. outgroup) $\times 3$ (target: pronorm, normative, antinorm) design used by Abrams et al. (2000, Study 2) but adds a further factor: leader (known vs. unknown). Group and leader were between-participants variables, and target was a within-participants variable. In all conditions, participants were aware that one of the targets was the leader. For half of the participants, the leader was not specified (unknown condition). For the remaining participants, the leader was specified as the antinorm deviant (known condition). Participants completed measures to establish whether they favored the ingroup over the outgroup and whether they correctly perceived the differences in policy positions among targets. Then they rated the typicality of each target and how favorable they felt toward each target.

\section{Method}

\section{Participants}

Fifty-three undergraduate psychology students participated as a course requirement. Participants were assigned randomly to conditions (12-14 participants per condition). The majority were female $(n=45)$, but, as no gender differences emerged in the analysis, this variable was not considered further.

\section{Procedure}

Following exactly the procedure adopted by Abrams et al. (2000, Study 2), participants were presented with a brief introduction to the topic of asylum seeking in Europe. A newspaper article was described, containing a series of graphs and tables reporting the numbers granted asylum in different European countries. Britain was the middle of the range. Participants then read a document entitled, "Survey Research on Asylum Seeking." This presented two opposing views regarding asylum regulations in Britain. An introductory paragraph highlighted the importance and emotiveness of the issues involved and provided (accurate) statistical information that 194,000 asylum seekers enter Britain each year, of which $21 \%(41,000)$ are granted asylum. The second paragraph gave a series of strong reasons why the numbers should be increased. The third paragraph provided information from a bogus survey conducted among the British Association of Immigration and Customs Officers (BAICO). This stated reasons why the numbers granted asylum should be reduced (arguments were matched for strength and number against those in the preceding paragraph).

At the end of this paragraph, we included the sentence,

In this survey the responses of the large majority of members reflected the official policy of the BAICO, namely that the proportion of asylum seekers who are ultimately granted permission to stay in Britain should be reduced by at least $30 \%$.
The final paragraph described a survey conducted among British psychology students and stated that the results indicated "widespread support for the status quo, namely that the current level of admissions for asylum seekers set by the present Government was about right." This reflected actual pretested attitudes regarding the asylum issue. Participants were then told that the survey would be continued and that they would be asked to give their impressions of other people who had participated.

\section{Judgments of Groups and Members}

Group evaluations. After reading the general introduction, participants were asked how favorable they felt toward BAICO and toward psychologists $(1=$ not at all, $7=$ extremely $)$.

Leadership manipulation and target evaluations. Next, participants viewed how six group members (labeled A to F) responded to 10 attitude items, as well as each member's specific recommendations about the percentage change in numbers that should be granted asylum. In the ingroup condition, the group members were all psychology students. In the outgroup condition, they were all BAICO members. A paragraph explained that from the survey of psychologists (BAICO), a discussion group was formed at one of the participating universities (offices). The paragraph also included the manipulation of leadership. In the unknown leader condition, it stated that, "The group included six members (A, B, C, D, E, F), one of whom was the chair of the Psychology Society [the manager of the local BAICO office]." In the known leader condition, the paragraph stated, "The group included the chair of the Psychology Society (Person E) [the manager of the office (Person E)]."

Members' attitude responses were represented on 21-point bipolar scales, which allowed precise manipulation of deviance. Across the 10 items, each member's attitudes did not vary by more than $+/-1$. Four members were depicted as holding normative beliefs for their group. Members B and E were deviant. Both were equally divergent from the normative members, and their attitudes fell outside of the range of the normative members. In the ingroup condition (psychology students), the four normative members' positions corresponded to the attitudinal positions of psychology students observed in our pilot work and our previous research (e.g., Abrams et al., 2000). These attitude positions each averaged 11, with a range from 10-12 across the attitude items. The recommended percentage change in people granted asylum averaged $0 \%$ across the normative members, with a range from $-5 \%$ to $+5 \%$. Deviants' attitudes were determined so that they fell outside the 95\% confidence interval (and differed significantly) relative to attitudes held by psychology students. The pronorm deviant (Person B) averaged 8 (range $=7-9$ ) on the attitude items and recommended an increase $(+15 \%)$ in the numbers granted asylum. The antinorm deviant (Person E) averaged 14 (range $=13-15)$ and recommended a reduction $(-15 \%)$ in the numbers granted asylum.

In the outgroup (BAICO) condition, the four normative members each averaged 17 on the attitude scales, with a range of $16-18$ across the items. The recommended percentage change in people granted asylum averaged $-30 \%$ across the normative members, with a range from $-25 \%$ to $-35 \%$. The pronorm deviant averaged 20 (range $=19-21)$ on the attitude items and recommended a large decrease $(-45 \%)$ in the numbers granted asylum. The antinorm deviant averaged 14 (range $=13-15)$ and recommended a 
smaller reduction $(-15 \%)$ in the numbers granted asylum. Thus, the average position of an antinorm deviant was the same in the ingroup and the outgroup conditions.

The policy orientation check asked participants to report the policy orientation of each target $(1=$ more open, $7=$ more closed). Participants then rated how typical the member was of their wider group and how favorable they felt toward each member $(1=$ not at all, $7=$ extremely $)$. At the end of the study, participants were asked whether they had any suspicions and were debriefed. No suspicions were expressed.

\section{Results}

As in Abrams et al.'s (2000, Study 2) study, we averaged the ratings of the four normative targets for judgment measures. Judgments of targets were analyzed using a Group (ingroup vs. outgroup) $\times$ Leader (known vs. unknown) $\times$ Target (pronorm, normative, antinorm) ANOVA, in which group and leader were between-participants variables and target was a within-participants variable.

As indicated earlier, the group evaluation and policy orientation checks showed that the ingroup was favored over the outgroup (see Table 1) and that the policy position of all targets was correctly identified (see Table 2).

\section{Typicality}

There was a significant main effect of target, $F(2,96)=4.68$, $p=.011, \eta^{2}=.09$ (see Table 2). There was also a significant main effect of group, $F(1,48)=29.34, p<.001, \eta^{2}=.38$. In line with the outgroup homogeneity effect (Park \& Rothbart, 1982), outgroup targets were perceived to be more typical $(M=5.92, S D=$ $1.29)$ than ingroup targets $(M=3.93, S D=1.41)$. These main effects were qualified by a significant interaction between Target $\times$ Group, $F(2,96)=5.14, p=.008, \eta^{2}=.10$. Tests of simple main effects revealed that the effect of group was larger for pronorm targets, $F(1,48)=28.32, p<.001, \eta^{2}=.37$, and antinorm targets, $F(1,48)=7.75, p=.008, \eta^{2}=.14$, than for normative targets, $F(1,48)=3.21, p=.08, \eta^{2}=.06$.

There was also a significant Leader $\times$ Target interaction, $F(2$, 96) $=5.16, p=.007, \eta^{2}=.10$. The effect of the leadership manipulation was not significant for pronorm targets, $F(1,49)=$ 1.15 , or for normative targets, $F(1,49)=1.81$, but was significant for the antinorm targets, $F(1,49)=6.49, p=.015, \eta^{2}=.12$. The antinorm target was viewed as less typical in the known condition $(M=3.80, S D=1.60)$ than in the unknown condition $(M=4.85$, $S D=1.66)$, consistent with the expectancy violation hypothesis but not with the conferral hypothesis. The main effect of leader and remaining interaction effects were nonsignificant $\left(F_{\mathrm{s}}<2.60, p \mathrm{~s}>\right.$ $.12)$.

\section{Favorability}

There was a main effect of group, $F(1,49)=8.57, p=.005$, $\eta^{2}=.15$. There were also significant Group $\times$ Leader, $F(1,49)=$ $4.25, p=.045, \eta^{2}=.08$, and Group $\times$ Target, $F(2,98)=36.03$, $p<.001, \eta^{2}=.42$, interaction effects. The latter is consistent with the black sheep effect and with the accrual hypothesis. Antinorm ingroup members were evaluated less favorably than normative and pronorm members, whereas antinorm outgroup members were evaluated more favorably than normative and pronorm members. The main effects of target and leader and the Leader $\times$ Target interaction were nonsignificant, $F_{\mathrm{S}}(1,49)<2.90$.

The Group $\times$ Leader and Group $\times$ Target interactions were qualified by a significant interaction between Group $\times$ Leader $\times$ Target, $F(2,98)=3.46, p=.035, \eta^{2}=.07$. We examined the simple Group $\times$ Leader interactions within each level of target. This was significant only for antinorm targets, $F(1,49)=8.31$, $p=.006, \eta^{2}=.15$. As shown in Figure 1, the ingroup antinorm target was rated less favorably when the target was a leader $(M=$ $2.43, S D=0.94)$ than when the leader was not known $(M=3.15$, $S D=1.73)$. The outgroup antinorm target was rated more favorably when the target was a leader $(M=4.83, S D=1.27)$ than when the leader was unknown $(M=3.43, S D=1.34)$. This indicates that antinorm deviance receives more extreme reactions when the deviant target is a leader, that is, the black sheep effect is augmented.

\section{Discussion}

Consistent with the SGD model, participants favored deviant targets from either group that showed relative support for the ingroup norm. Even though the antinorm ingroup target and the antinorm outgroup target expressed an identical attitude, participants were significantly more favorable toward the outgroup target. All these findings replicate those from Abrams et al.'s (2000, Study 2) study.

This study shows, for the first time, that perceptions of typicality and evaluations are both affected by the leadership role. Typicality judgments were broadly in line with our previous research showing that ingroup antinorm deviants are judged as less typical than pronorm deviants (Abrams et al., 2000, 2002). When the antinorm target was a leader, this seemed to exaggerate his or her lack of prescriptive normativeness. This is in line with the expectancy violation hypothesis in the sense that antinorm leaders violate expectations more than antinorm members.

We were specifically interested in whether an established leadership role would moderate favorability toward targets. The conferral hypothesis was that reactions should have been more positive toward an antinorm leader than an identical antinorm target because leadership gives the right to define the group prototype. This hypothesis was not supported. The accrual hypothesis was that the right to leadership accrues from adherence to prescriptive norms. It would follow that antinorm targets should not be leaders. This is shown by the black sheep effect, consistent with the accrual hypothesis. In line with the expectancy violation hypothesis, for ingroup targets, the antinorm leader was evaluated more negatively than the antinorm nonleader. However, this hypothesis might conceivably predict a similar pattern for outgroup targets because it would be equally surprising to learn that an outgroup leader is antinormative. Instead, we found that antinorm outgroup leaders are favored more than antinorm outgroup members. This is consistent with the SGD model because endorsement of the ingroup normative direction from a high-status outgroup member would be especially validating for the ingroup. 


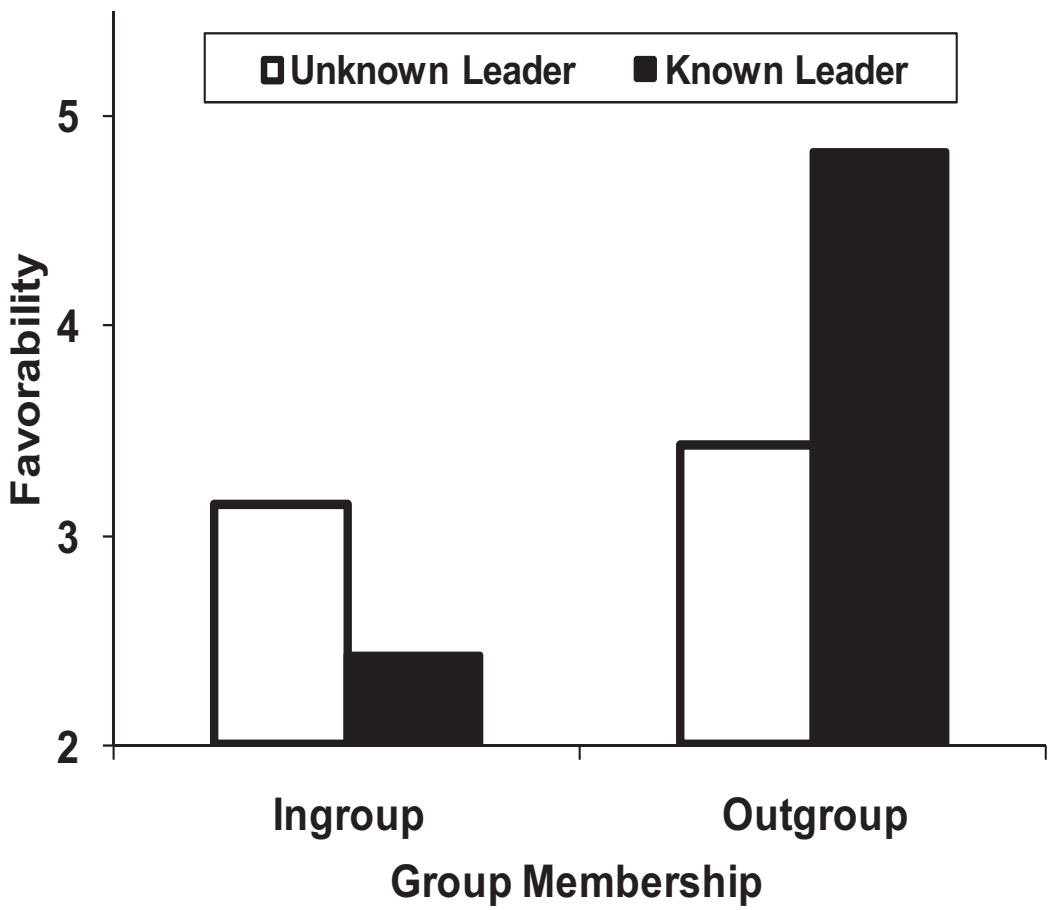

Figure 1. Study 1: Mean favorability to antinorm deviants as a function of group membership and whether they are known to be the leader.

\section{Study 2: Ex-Leader}

Study 1 demonstrated the effect of antinorm deviance on judgments of established leaders from an ingroup and outgroup. The remaining studies focus only on judgments of ingroup members (following the focus of studies by Haslam and colleagues; e.g., Haslam \& Platow, 2001) to examine how different phases of leadership might affect typicality perceptions and evaluations of targets. We also note that the effects of leadership in Study 1 were restricted to the antinorm targets, indicating that they were specifically a result of the leadership role for that target. Thus, as outlined in the "Analytic Strategy" section, analyses for the remaining studies focus on the effects of leadership on antinorm targets in ingroups.

An ambiguity arising from Study 1 was that we did not state clearly whether the currently established leader had previously been a leader. Study 2 was conducted to determine whether antinorm ex-leaders are evaluated differently from nonleaders. The manipulation of leader was modified to ensure that participants believed that the antinorm target did not hold the leadership role currently and would not in future. Only the conferral hypothesis suggests a distinction between an ex-leader and a member. Specifically, assuming that an antinorm ex-leader may de facto have greater prototypicality, it could be predicted that this target should be judged to be more typical and evaluated more positively than an antinorm member. The accrual hypothesis does not distinguish between an antinorm member and an antinorm ex-leader because neither is a current leader and both are equally nonprototypical.

Study 2 used a between-participants design to compare evaluations of antinorm targets who were or were not ex-leaders (leader: known vs. unknown). The average judgments about other mem- bers were included as a covariate. Participants were informed that the group was going to submit evidence to a government committee on the issue of asylum seeking. In the known condition, the antinorm target was specified as the previous leader of the group who would not lead the group in the forthcoming meeting. In the unknown condition, no leader was specified.

\section{Method}

\section{Participants}

Forty-two first-year psychology undergraduate students participated as part of course requirements. Participants were assigned randomly to condition (21 participants per condition). The majority of participants were female $(n=34)$, but, as no gender differences emerged in the data analysis, this variable was not considered further.

\section{Procedure}

The procedure was identical to Study 1, but only ingroup targets were presented. In the known condition, participants were told,

The Government set up a taskforce last year to consider evidence from different groups on the asylum issue as part of evidence based decision making, and there will be another next year. Representatives from different groups will be appointed by the task force to participate in these discussions, including Psychologists and BAICO. Person E was appointed by the task force to represent Psychologists and led the group last year (but will not next year). Please look at the attitude profiles from each participant's survey responses. 
In the leader unknown condition, the leadership information simply stated, "Someone from this discussion group will be chosen to represent Psychologists and lead the group." Participants then completed the same measures as for Study 1.

\section{Results and Discussion}

Group evaluation measures and policy orientation checks confirmed that the ingroup was favored over the outgroup (see Table 1) and that the policy position of all targets was identified correctly (see Table 2). In line with accrual hypothesis, the antinorm target was perceived as less typical and judged less favorably than the other targets (see Table 2). However, there were no significant effects of leader for judgments of typicality, $F(1,39)=0.04, p>$ .80 , or favorability, $F(1,39)=0.05, p>.80$. The absence of significant differences means that we found no support for the expectancy violation or the conferral hypotheses. Taken together with Study 1, the results suggest that, when considering antinorm targets, participants regard ex-leaders much like regular members but they regard currently leaders differently from regular members. This is consistent with the idea that phase of leadership moderates judgments.

\section{Study 3: Future Leader}

Study 3 takes the consideration of phase a step further by investigating judgments of antinormative future leaders. Prospective leaders often offer aspirations for change in their manifestos, and many incoming leaders set great store by their first 100 days. This "honeymoon period" may represent an opportunity to define new group norms. Thus, Study 3 used a between-participants design to compare evaluations of antinorm targets who were or were not known to be the future leader (leader: known vs. unknown.). The average judgments about other members were included as a covariate.

\section{Method}

\section{Participants}

Forty-six first-year undergraduate psychology students participated as a course requirement. Participants were assigned randomly to conditions ( 23 per condition). The majority of participants were female $(n=41)$, but, as no gender differences emerged in the data analysis, this variable was not considered further.

\section{Procedure}

The procedure was similar to Studies 1 and 2 and included the same dependent variables. The manipulation of leadership was altered to refer to future leadership. In the unknown leader condition, participants were informed, "One of these people will represent this group." In the known leader condition, they were told, "Person E has been chosen to represent Psychologists."

\section{Results}

The group evaluation and policy orientation checks confirmed that the ingroup was favored over the outgroup (Table 1) and the policy position of all targets was identified correctly (Table 2).

\section{Typicality}

Table 2 shows that the antinorm targets were judged to be less typical than other targets. There was no effect of the covariate, $F(1$, $42)=0.30$. The means for the antinorm targets were more consistent with conferral than with expectancy violation; the antinorm leader was perceived as somewhat more typical $(M=3.91, S D=$ $1.08)$ than the antinorm member $(M=3.41, S D=1.18)$, however this difference was not statistically significant, $F(1,42)=2.14, p$ $=.15, \eta^{2}=.05$.

\section{Favorability}

Table 2 shows that antinorm targets were judged less favorably than other targets, consistent with the accrual hypothesis. There was no significant effect of the covariate, $F(1,43)=0.01$. There was a significant effect of leader, $F(1,43)=6.70, p=.01, \eta^{2}=$ .14. Evaluations were more favorable when the antinorm target's role was known $(M=4.04, S D=1.36)$ than when it was unknown $(M=3.00, S D=1.31)$. Consistent with the conferral hypothesis, but not the expectancy violation hypothesis, being a future leader resulted in more positive reactions to antinorm targets.

\section{Discussion}

In Study 3, participants were told that an antinorm member of the group would act as the group's representative in a future external situation. Antinorm targets that were identified as future leaders were judged more positively than when the leadership role was unknown. This pattern contrasts with the relative downgrading of the antinorm leader in Study 1 (established leader) and is consistent with the idea that accrual and conferral may be weighted differently at different phases of leadership.

The future leadership role was clear in Study 3, but we did not separate it from current occupancy of that role. This leaves some ambiguity over the comparison with Study 1. Specifically, in Study 3, the judgments of the future leader position may have confounded the effects of accrual and conferral on current leadership and their effects on future leadership. Therefore, one aim of Study 4 was to ensure that the future leader was clearly identified as a future but not a current leader (similar to the clarification used for Study 2 with respect to ex-leadership).

A further possibility not examined previously is that leaders may be judged differently from members simply because they are more salient and attract more attention. Fiske (1993) showed that followers pay close attention to leaders, and Hogg (2001b) also highlighted "status based structural differentiation within the group into leader(s) and followers" (p. 205). Therefore, salience might increase the processing of information about a leader and might extremitize judgments. If this occurs, then we could have expected (but did not find) an effect of leadership in Study 2. However, it is possible that in the case of ex-leaders, people pay less attention because the leadership role is inconsequential. Therefore, it remains possible that the effects of leadership reported in Study 3 may have been due to heightened salience of the antinorm leader. Study 4 investigates this possibility by drawing greater attention to the antinorm member.

\section{Study 4: Future Leader and Salience}

Study 4 was a between-participants design (leader: known vs. unknown), with judgments of the antinorm target as dependent 
variables and judgments of other members as a covariate. The manipulation of future leadership was clarified to ensure that participants did not believe that the leadership role had potentially previously been held by the antinorm deviant. In addition, in the unknown condition, we drew attention to the antinorm target.

The accrual hypothesis suggests that the antinorm leader will be judged similarly to the antinorm member. Both should be evaluated less favorably than other members. The conferral hypothesis predicts that the antinorm leader will be judged more favorably than the antinorm member. If the effects in Study 3 are attributable to salience, then we would expect less difference in the judgments of leader and nonleader targets. If, in contrast, conferral occurs despite salience, then we would expect equal or greater difference than was observed in Study 3.

\section{Method}

\section{Participants}

Forty-three first-year psychology undergraduate students participated as part of course requirements. Participants were randomly assigned to conditions (21 in the future condition, 22 in the salient condition). The majority of participants were female $(n=35 ; 1$ participant did not report gender), but, as no gender differences emerged in the data analysis, this variable was not considered further.

\section{Procedure}

The procedure slightly modified the instructions given in Study 3. In the leader known condition, we clarified that the target had not been the representative of the group previously. Participants were told,

From the survey of Psychologists a discussion group was formed at one of the participating universities. The Government set up a taskforce in 2001 to consider evidence from different groups on the asylum issue as part of evidence based decision making, and there will be another in 2003. Representatives from different groups will be appointed by the taskforce to participate in these discussions, including Psychologists and BAICO. Person E has been appointed by the taskforce to represent Psychologists and lead the group in 2003 (but was not in 2001). Please look at the attitude profiles from each participant's survey responses.

In the leader unknown condition, participants were given the same information but only that there would be a leader; the identity of the leader was not specified. Furthermore, the antinorm target was made salient and highlighted for participants' attention. Participants were told, "Someone from this discussion group will be chosen to represent Psychologists and lead the group. Please look at the attitude profile from each participant, as well as Person E's survey responses."

Participants completed the measures, and they were then debriefed about the aims of the study and asked if they had any suspicions. No accurate suspicions were reported.

\section{Results}

The group evaluation and policy orientation checks confirmed that the ingroup was favored over the outgroup (Table 1) and the policy position of all targets was correctly identified (Table 2).

\section{Typicality}

Table 2 shows that the antinorm targets were judged to be less typical than other targets. There was no effect of the covariate, $F(1$, $39)=0.01$. There was a significant effect of leader, $F(1,39)=$ $4.57, p=.039, \eta^{2}=.11$. The antinorm target was judged to be significantly more typical in the known condition $(M=3.75$, $S D=1.21)$ than in the unknown condition $(M=3.00, S D=1.02)$.

\section{Favorability}

Table 2 shows that the antinorm targets were judged more favorably than other targets. There was no effect of the covariate, $F(1,39)=0.00$. There was a significant effect of leader, $F(1$, $39)=6.73, p=.013, \eta^{2}=.15$. Participants were more favorable when the antinorm deviant was the group's future leader $(M=$ $4.20, S D=1.51)$ than a salient member $(M=3.09, S D=1.19)$.

\section{Discussion}

Study 4 disambiguated whether the future leader target was a future or current leader (cf. Study 3 ) and also contrasted that status with that of a similar member to whom attention has been directed. Study 4 shows that when an antinorm member is known to be a future leader, that member is judged to be more typical and is evaluated more favorably than when that member is simply made salient.

Study 4 reinforces the finding from Study 3 that future leaders are upgraded. This contrasts with the relative downgrading of the antinorm established leader in Study 1 . The results in Study 4 are again consistent with the idea that accrual and conferral may be weighted differently at different phases of leadership. Moreover, by ensuring that the future leader was clearly identified as a future and not a current leader, this finding disambiguates the distinctive effect of future leadership.

On the basis of Hogg's (2001b) and Fiske's (1993) work, we conjectured that the effects of leadership reported in Study 3 may have been due to heightened salience of the antinorm leader. Study 4 investigated this possibility by specifying the antinorm member as a future leader versus simply drawing attention to the antinorm member.

It is important to note that typicality judgments differed for the two targets in Study 4 but not Study 3. This might seem consistent with the idea that the salience manipulation affected typicality judgments in Study 4. However, comparison of the means and standard deviations for typicality of the unknown member in Study $3(M=3.41, S D=1.18)$ and the salient member in Study $4(M=$ $3.00, S D=1.02$ ) indicate that the salience manipulation did not result in a significant reduction in perceived typicality, $t(43)=$ $1.23, p>.10, d=0.38$. The similar comparison for the future leader in Study $3(M=3.61, S D=1.31)$ and in Study $4(M=$ $3.75, S D=1.21$ ) also revealed no significant difference, $t(42)=$ $0.36, p>.30, d=0.10$. Thus, although the difference between targets is larger within Study 4 than within Study 3, there is no evidence that salience was responsible for shifts in perceived typicality of the nonleader.

The effect sizes for favorability judgments in the two studies are almost the same (.14 and .15 , respectively). There was no significant difference between the means for the unknown member in 
Study $3(M=3.00, S D=1.31)$ and the salient member in Study $4(M=3.09, S D=1.19), t(43)=0.24, p>.40, d=0.07$. Similar comparison of the future leader in Study $3(M=4.04, S D=1.36)$ and the salient member in Study $4(M=4.20, S D=1.51)$ was also nonsignificant, $t(42)=0.36, p>.30, d=0.11$.

These results confirm that when an antinorm member has been identified clearly as a future leader and when such a member has merely been made salient, participants regard the former as more typical and judge that member more favorably. These findings are consistent with Study 3, and there is no evidence that the different operationalization of the nonleader versus future leader status caused different (other than slightly larger) effects. Thus, Study 4 strongly supports that future leadership can partially offset the unfavorable reactions usually afforded antinorm group members.

The accrual hypothesis suggests that antinorm targets will be judged less favorably than normative and pronorm targets. This hypothesis was supported. The expectancy violation hypothesis was not supported. The conferral hypothesis predicts that the antinorm leader will be judged more favorably than the antinorm member. This hypothesis was supported. Moreover, there was no support for the idea that the more favorable judgments of future leaders are a result of increased leader salience.

\section{Study 5: Innovation Credit}

The previous studies focused on judgments of group members as indexes of accrual or conferral processes. The evidence across these studies is generally consistent with the idea that conferral is more likely in the case of a future leader than other types of leaders. Study 5 examined responses to antinorm members who were a past leader, a nonleader, or a future leader (responses to other members were included as a covariate). In addition, Study 5 used a different set of indexes to reflect members' willingness to support the agenda of an antinormative leader.

We use the term innovation credit to characterize the extent to which members of a group will endorse leaders' deviation from existing norms. Organizations frequently call on their leaders to bring about change (Yukl, 2002), and often organizations are prepared to invest substantially in salary and other aspects of remuneration to attract the best leaders. Innovation credit is likely to reflect people's acceptance of the leader's legitimacy and right to determine the prescriptive norm. Thus, we operationalized this concept using two measures, license to innovate and remuneration. The license to innovate measure is new, and the remuneration measure is adapted from a previous study that did not involve leadership (Abrams et al., 2000).

The accrual hypothesis would hold that less prescriptively normative members should be given less innovation credit. This hypothesis does not distinguish between leaders and nonleaders; however, it does speak to differences between antinormative and other targets. Specifically, accrual should be lower for antinorm targets. Expectancy violation might lead us to expect that this denial may be greater in the case of antinorm leaders than in the case of antinorm nonleaders because of the greater breach of trust by the former. However, this effect would be common to past and future leaders. The conferral hypothesis would predict that a leader should be granted greater license to innovate by virtue of their position, even if that leader is antinormative (cf. Lord, 1977).
The present study more directly tests the phase hypothesis. In line with findings from Studies 1-4, we expect that responses to antinorm leaders will depend on the phase of leadership. Whereas opportunities to innovate may be irrelevant or deemed unnecessary in the case of a past leader, they may be advantageous in the case of a future leader. Thus, we expect conferral to result in greater innovation credit for only future leaders.

\section{Method}

\section{Participants}

Fifty-six introductory undergraduate psychology students participated as a course requirement. Participants were assigned randomly to conditions (16-20 per condition). The majority of participants were female ( $n=43)$, but, as no gender differences emerged in the data analysis, this variable was not considered further.

\section{Procedure}

The manipulation of the antinorm target's status was changed from Study 4 to clarify the leader conditions and to ensure direct comparability across conditions. We also altered the control condition so that it made no mention of leadership at all (as in Abrams et al., 2000).

All participants were informed,

From the survey of the Psychologists a discussion group was formed at one of the participating universities. The group included six members (we have labeled A to F). The government set up a taskforce in 2005 to consider evidence from different groups on the asylum issue as part of evidence based decision making and there will be another in 2007.

In the leadership conditions, it was explained that group leaders could only serve for one term and the leadership for the psychologist group was determined as follows:

Representatives from different groups will participate in these taskforce discussions, including Psychologists and BAICO. Each year that the taskforce meets, a civil servant provides instructions and a leader is appointed. Civil service rules state that the group leader must change each year so that no member has two consecutive years as leader.

In the future leader condition, participants were told, "Person E has been appointed by the taskforce to represent Psychologists and to lead the group in 2007, so will be the new leader starting next year." In the past leader condition, participants were told, "Person E was appointed by the taskforce to represent Psychologists and to lead the group last year (2005), so is not the leader this year and will not be again."

After completing the group and policy checks, participants completed the license to innovate measure: "To what extent do you think each member should be able to innovate and come up with new ideas for the psychology group?" $(1=$ not at all, $7=$ completely). Next, they completed the remuneration measure. They were asked to,

Imagine these 6 psychology students were responsible for making decisions on an appeal committee for Asylum applications. The com- 
mittee is paid $£ 290$ for making each decision. Members must be paid at least $£ 10$ and at most $£ 120$, but the total must equal $£ 290$. Write down how much you think each person should be paid.

At the end of the experiment, participants were debriefed and asked if they had any suspicions. No accurate suspicions were reported.

\section{Results}

The group evaluation and policy orientation checks showed, as expected, that the ingroup was favored over the outgroup (see Table 1) and that the policy position of all targets was correctly identified (see Table 2). Overall responses to pronorm, normative, and antinorm targets are shown in Table 3. This shows that antinorm targets were given less license to innovate, consistent with the accrual hypothesis.

License to innovate and remuneration were analyzed using leader (future vs. past vs. none) ANOVAs, including the average ratings of other targets as a covariate in each analysis.

\section{Innovation Credit: License to Innovate}

There was a significant effect of the covariate, $F(1,51)=45.35$, $p<.001, \eta^{2}=.47$. There was also a significant effect of leader, $F(2,51)=7.13, p=.002, \eta^{2}=.22$. Contrasts showed that license to innovate was significantly greater for an antinorm future leader $(M=5.40, S D=0.94)$ than for an antinorm past leader $(M=$ $4.35, S D=2.16), t(52)=3.00, p=.004, d=0.83$, or an antinorm nonleader $(M=4.13, S D=1.78), t(52)=3.46, p=.001, d=$ 0.96. There was no difference in license to innovate between the antinorm past leader and the antinorm nonleader, $t(52)=0.68, p=$ .50 .

\section{Innovation Credit: Remuneration}

There was a significant effect of the covariate, $F(1,49)=15.32$, $p<.001, \eta^{2}=.24$. There was also a significant effect of leader, $F(2,49)=4.11, p=.022, \eta^{2}=.14$. Contrasts showed that the future leader was allocated more funds $(M=60.74, S D=31.16)$ than the antinorm past leader $(M=44.98, S D=31.74), t(50)=$ $2.65 p=.011, d=0.75$, or the antinorm nonleader $(M=37.53$, $S D=16.22), t(50)=2.25 p=.029, d=0.64$. Remuneration did not differ significantly between the past and nonleader, $t(50)=$ $0.24, p=.82$.

\section{Discussion}

Study 5 disambiguated whether the leader had ever previously led and the period of tenure. The study also allowed a direct comparison between past leader (Studies 1 and 2), no leader
(Abrams et al., 2000, Study 2), and future leader (Studies 3 and 4). Finally, the study extended the previous research by examining two new dependent variables, license to innovate and remuneration, which seem particularly relevant for leadership.

The findings are consistent with, and extend, the cumulative results from other studies. Antinorm targets are treated less favorably than other members, consistent with the accrual hypothesis. However, this pattern differs depending on whether the antinorm target is a past leader, member, or future leader. Specifically, contrary to past and nonleaders, future leaders are given greater innovation credit. Future leaders are given more scope to express attitudes that diverge from the current group norm and are rewarded more for doing so. These findings are consistent with results from Studies 3 and 4, showing that antinorm future leaders are judged more favorably than other members who hold antinorm positions.

\section{Integrative Analyses}

To evaluate the overall support for the three hypotheses, we conducted meta-analytic integration for evaluations of targets across Studies 1-4. For the accrual hypothesis, we tested the main effects of target (see Table 2). For typicality, mean $r=.30, Z=$ $5.17, p=1.23$ E-7. The chi square $(d f=3)$ for the diffuse comparison of effect sizes was $2.74(p=.43)$, showing that the effect sizes did not differ significantly across studies. For favorability, mean $r=.25, Z=4.21, p=1.27 \mathrm{E}-5$. The chi square $(d f=3)$ for the diffuse comparison of effect sizes was 6.17 ( $p=$ .10), showing that the effect sizes did not differ significantly across studies. Thus, across Studies 1-4, the accrual hypothesis was supported.

To evaluate the effects of leadership, we first examined the diffuse comparison of effect sizes across Studies $1-4$. The $Z$ for comparison was $3.31(p<.001)$, indicating that effect sizes differed significantly across studies. Thus, the expectancy violation hypothesis is not supported because that hypothesis would predict a similar pattern of differences between leaders and nonleaders across studies. However, the phase hypothesis predicted that future leaders would be evaluated more positively than nonleaders, whereas current and ex-leaders would be evaluated equally or less positively than nonleaders. Therefore, we conducted a focused comparison of effect sizes between Studies 1 and 2 versus Studies 3 and 4 . This confirmed that the mean effect size in Studies 1 and 2 (mean $r=-.13, Z=1.25, p>.80$ ) was significantly different from the mean effect size in Studies 3 and 4 (mean $r=.38, Z=3.51, p<.001$ ).

\section{General Discussion}

In this article, two preliminary investigations and five experiments, involving 567 participants, provide converging evidence on

Table 3

Judgments of License to Innovate and Remuneration as a Function of Target in Study 5

\begin{tabular}{lcccc}
\hline \multicolumn{1}{c}{ Variable } & Pronorm & Norm & Antinorm & ANOVA statistic \\
\hline License to innovate & $5.14(1.30)$ & $4.73(1.45)$ & $4.66(1.76)$ & $F(2,106)=3.88, p=.024, \eta^{2}=.07$ \\
Remuneration & $48.70(23.65)$ & $44.20(10.27)$ & $48.85(29.00)$ & $F(2,100)=0.55, p=.58, \eta^{2}=.01$ \\
\hline
\end{tabular}

Note. $\quad$ ANOVA $=$ analysis of variance. 
how the leadership role affects reactions to antinorm deviants. The SGD model (Marques, Páez, \& Abrams, 1998) assumes that group members who undermine the ingroup norm, whether leaders or not, should be downgraded relative to more validating members. This was supported in all studies. We considered alternative hypotheses for situations when an antinorm deviant is also a leader (Abrams et al., 2005; Randsley de Moura \& Abrams, 2002), three of which were examined directly in this series of studies.

First, the accrual hypothesis was that evaluations of antinorm leaders should primarily reflect the right to lead, accrued from their endorsement of prescriptive ingroup norms. (These norms are also convergent with the group prototype in the present research.) Second, the expectancy violation hypothesis was that reactions to antinorm leaders would be more negative than reactions to members because people should not expect leaders to hold antinormative positions. Third, the conferral hypothesis was that occupancy of the leadership role could establish the antinorm leader a priori as relatively more prescriptively normative than an antinorm nonleader.

\section{Summary of Findings}

\section{Accrual}

The social identity approach to leadership (e.g., Haslam, 2001; Hogg, 2001c; Hogg \& van Knippenberg, 2003; Turner \& Haslam, $2001)$ emphasizes the accrual process, namely that members who are more nonprototypical should be evaluated less highly as leaders. The evidence is generally consistent with the idea that antinorm deviants, whether leaders or not, are evaluated less favorably than other members. However, the present evidence demonstrates systematically that antinorm deviants who are future leaders will not be rejected out of hand, despite their lack of prototypicality. Both the preliminary evidence and the differences between studies provide evidence supporting alternative hypotheses.

The two preliminary investigations suggested that (a) adherence to prescriptive norms and innovation are both attributes that people also believe characterize leadership and (b) innovation was regarded as more natural for a future than a past leader. Thus, it seemed likely that both accrual and conferral play a role in reactions to antinorm leaders.

\section{Expectancy Violation}

In Studies 1-4, we compared reactions to antinorm members with reactions to antinorm leaders. We found an antinorm member was judged similarly to an antinorm ex-leader (Study 2), more favorably than an antinorm established leader (Study 1), and less favorably than a future leader (Study 3). It is notable that in Study 4 , the salient antinorm member was also judged less favorably than the antinorm future leader, indicating that salience is not a plausible explanation for judgments of future leaders. In sum, the expectancy violation hypothesis was only supported in Study 1 (ingroup established leader) and was not supported in four studies.

\section{Conferral}

If conferral occurs, then we would expect the antinorm leader to be favored more than an antinorm member. In the case of a future leader, the evidence (Studies 3 and 4) clearly supported this prediction. However, when the leader was either current or past (Studies 1 and 2), there was no support for the conferral hypothesis.

\section{Phase}

We proposed that people may apply different criteria for judging antinorm leaders, depending on the phase of their leadership. Specifically, we proposed that conferral was most likely for future leaders. The data from Studies 1-4 were consistent with this hypothesis. However, several potential ambiguities in Studies 1-4 needed to be addressed. One was to clarify that the future leader was not also currently occupying that role (this was rectified in Studies 4 and 5). Study 5 also addressed the problem that there was no direct comparison between a future and past leader in Studies $1-4$, as well as ensuring that the rules governing occupancy of the role were similar for both the past and future leaders. Another important issue raised by gaps in previous research was whether reactions to nonnormative leaders might just as easily reflect a general class of reactions to nonnormative members and not be distinctive to leadership. This was addressed in all studies, and Study 5 provided a more direct comparison with the results of Abrams et al.'s (2000, Study 2) work by including a no-leadership control condition.

Taken across the five studies, judgments of nonleader antinorm targets are consistent, regardless of whether there is another member of the group who might be the leader. Moreover, the present research also shows that leadership does make a difference to evaluations of antinormativeness, but not always the same difference. The findings disambiguate and extend the conclusions reached by Haslam and colleagues (e.g., Haslam \& Platow, 2001; Platow \& van Knippenberg, 2001). In line with that research and the accrual hypothesis, group members generally were less favorable toward antinorm members than other members. However, in line with the conferral and the phase hypotheses, antinorm future leaders were treated more favorably than antinorm members or antinorm ex-leaders.

As well as confirming the pattern of differences from Studies 1-4, Study 5 also explored innovation credit. Future but not past leadership resulted in increased payment and increased license to innovate. Indeed, the antinorm future leader was given greater innovation credit than all other group members. This suggests strongly that people may be willing to entrust future leaders with freedom to adopt innovative or different positions from established group norms and thereby to be somewhat excused for their deviance.

\section{Theoretical Contribution and Implications}

The present research contributes both to leadership and SGD theory, and we hope it will stimulate a more extended theoretical analysis of the phenomena of leadership phase, innovation, and deviance. The findings raise theoretical questions for the social identity approach to leadership. It may be difficult to reconcile prototypicality-based endorsement (accrual) with the finding that there can be higher endorsement of an antinormative leader than a normative member (Study 5) or that a future leader who is antinormative invites more positive reactions than a member who is 
antinormative (Studies 3, 4, and 5). Attribution processes are included in Hogg's (2001b, 2001c) leadership theory, and attributions about the leader's attitudes, motives, or behavior are deemed part of the psychological process regarding leader evaluation. Specifically, on the basis of Hogg's (2001b, 2001c) analysis, we think it is possible that new group leaders are not subject to the same level of attribution bias as emergent leaders. Group members may attribute deviance displayed by a new leader to situational rather than dispositional factors. Investigating these possibilities seems likely to be a fruitful avenue for future research.

It is also possible that future leaders who deviate from group norms may be regarded as potential "entrepreneurs of identity" (Reicher \& Hopkins, 2003). Such entrepreneurship has been characterized as a situation in which leaders are expected to act creatively on behalf of the group to bolster the existing prototype or affirm the prototypicality of themselves and other members. Innovation and creativity could plausibly be group norms (see Adarves-Yorno, Postmes, \& Haslam, 2007). We might expect that groups with a progressive norm (Adarves-Yorno et al., 2007) would endorse deviant leaders more than groups without such a norm and that this might be further heightened when considering a future leader, particularly as future leaders themselves may offer opportunities for progression and change. However, the entrepreneurship idea would probably still hold that such norms would prohibit endorsement of a leader who advocated a counternormative position (e.g., to be less progressive or innovative).

The SGD model has not explicitly set out why a future leader should be given scope to change prescriptive norms in an antinorm direction. However, the SGD approach allows that ingroup validity can be sustained with reference to a variety of norms that can serve a prescriptive function. For example, some norms are more generic (Bown \& Abrams, 2003) and groups may compete to be better than one another in terms of those norms (e.g., moral norms; Abrams et al., in press; Marques et al., 2001). It is possible that future leaders may be granted opportunities to redefine group norms when these increase ingroup validity by being more widely accepted in a wider social context. Ex- and established leaders may be trapped by the existing normative positions, whereas future leaders may be seen as offering new opportunities for validation on new dimensions.

The present research shows that future leaders who challenge, rather than merely promote, the prescriptive norm can be, under some circumstances, endorsed more than similar members. Acceptance of an antinorm leader may also be affected by the prospect of material gains for the group. For example, a political leader that adopts a more centrist position than the party's traditional differences from an opposing party might offer more potential for success on a wider level (by attracting voters) and, therefore, the leader's deviance can be tolerated (Morton, Postmes, \& Jetten, 2007) We might expect that this would only occur if differences between groups were prescribed or if endorsing an antinorm leader could still allow for sufficient intergroup distinction. Furthermore, in this situation, it seems likely that material success would coincide with greater social validation of the group (i.e., more consensual support for its changed norms). Thus, a question for future research is whether leader survival is dependent on the perceived material outcomes for the group (e.g., increased support from outside, increased resources, increased power, and so forth), independently of a norm-validation motive, which SGD would suggest.
The phase effect demonstrated by the present research is consistent with the idea that established leaders are bound by an implicit contract of prototypicality (cf. Haslam et al., 2001) and loyalty (cf. Abrams et al., 2002, in press; Levine \& Moreland, 2002; Zdaniuk \& Levine, 2001). In contrast, future leaders appear to be granted greater license to be independent and to gain from a conferral effect (cf. Hollander, 1958). Future leaders seem to be entrusted to know what is best for the group. People sometimes speak of a honeymoon period for new leaders, in which they may exert some independence and try to define a new direction for the group. It is possible that this effect may be heightened, particularly when the group has been previously unsuccessful or marginalized (cf. Coser, 1962; Homans, 1974; Levine, Moreland, \& Choi, 2001; Morton et al., 2007).

An important question for future research is how long this period might last. Leaders differ in their capacity to seize on and change the norm or redefine the group's agenda (a successful example being Tony Blair, who led "New Labour" for 10 years as prime minister of Great Britain, and a less successful example being Menzies Campbell, who lead the Liberal Democrat Party for only a brief period before having to resign). As time goes by, pressure may build on the leader to become more normative. Ultimately, noncompliant leaders may be ousted from their position. One reason why political parties change leaders may be that this provides a psychologically acceptable means of shifting policy via a single voice rather than having to wait for statistical shifts in group norms amongst the membership.

To summarize, future research is needed to investigate how much a leader's survival depends on (a) the leader's assimilation back toward the prior group norm (leader changes) and (b) the group's assimilation to the leader's position (group changes), as well as whether it is simply a time-limited license to innovate that is granted, regardless of what the leader does (time based).

These questions also relate to Levine and Moreland's group socialization model (e.g., Levine \& Moreland, 1994; Levine, Moreland, \& Hausmann, 2005), which emphasizes the relative contribution new, full, and old timer group members can make to a group. It may be that established leaders are in a particularly significant position in this respect because, by deviating from the group norm, they can cause significant damage to that norm. In contrast, ex-leaders pose no more threat than other members. In the case of future leaders, whose potential contribution is as yet unrealized, members may be willing to allow greater latitude before regarding deviance as a threat. Further light would be cast on these possibilities if future research examined the way past, present, and future leadership roles impact on perceptions of contributions shared by the leader and the group.

\section{Limitations}

The present effort examines positional leadership, which is particularly common in organizational contexts (e.g., leaders are appointed externally or members join teams that already have leaders). These findings suggest that organizations that wish to change may find it easier to do so by appointing new leaders because members will be less resistant to potentially antinorm positions these leaders may express. An important question that was beyond the scope of the present work is how deviance affects emergent leadership (e.g., Fielding \& Hogg, 1997) or how the 
procedures by which leaders are appointed affect responses to leader deviance (Morris, Hulbert, \& Abrams, 2000). Research extending the present studies (Xiang \& Masser, 2006) suggests that whether the leader is appointed or has been elected makes no difference to the pattern of results. This remains an important issue for further investigation.

The findings from the present scenario-based studies are consonant with other evidence that is more field based (e.g., Bown \& Abrams, 2003; Fielding \& Hogg, 1997), and the scenarios seemed to be engaging and meaningful to the participants. Nonetheless, it would be useful to explore these questions using evidence from real groups and real leaders and with observational and unobtrusive data collection (e.g., through archival methods).

A further limitation is that, in common with much research on deviance and most of the social identity theory leadership research, we only considered deviance in terms of unidimensional prescriptive norms. It would also be interesting for future work to explore the limits of conferral effects, as well as whether conferral might come into play for current leaders under some circumstances (e.g., if the leader has built a high level of trust).

\section{Conclusions}

The present research is the first to test experimentally the independent effects of role and deviance on evaluations of antinorm leaders. The research presents seven independent investigations that clarify substantial ambiguities in previous research on deviant leadership, which has not distinguished empirically between leaders and members. It has also advanced previous research by distinguishing between different phases of leadership, showing that these affect the way deviant leaders are evaluated. We have also shown, for the first time, the implications of accrual and conferral for the innovation credit that leaders are given by members. We demonstrated systematically that antinorm future leaders are not rejected out of hand, as the social identity theory approach to leadership might suggest, but are instead given special license to innovate.

We began by asking what scope a leader may have to take a group in a new direction, particularly when that direction may move toward the norms of an opposing group. This problem confronts leaders in many organizations and political systems. These leaders may face a tension between their group's desire for intergroup differentiation and a need for moderation and objectivity to gain popular support or to implement effective policy. This dilemma is also faced by leaders who aim to broker intergroup peace and harmony with an outgroup. Hence, it is highly relevant to issues such as the Middle East peace agreements as well as situations such as that in Northern Ireland.

In conclusion, the present studies demonstrate that evaluations of antinormative group members depend both on the role of the member (leader vs. member) and the phase of leadership. As well as replicating past patterns of member evaluations from the SGD model, this evidence extends prior research on social identity and leadership. It also lends support to the idea from the SGD model that judgments of group members are particularly orientated toward establishing validity of the ingroup norm. Both accrual and conferral effects occur, but they are weighted differently according to the phase of leadership. Innovation credit is accorded to future, but not to established or ex-, leaders who challenge prevailing norms. Further research should examine the conditions that facilitate or inhibit these accrual and conferral effects.

\section{References}

Abrams, D., Marques, J. M., Bown, N. J., \& Dougill, M. (2002). Anti-norm and pro-norm deviance in the bank and on the campus: Two experiments on subjective group dynamics. Group Processes and Intergroup Relations, 5, 163-182.

Abrams, D., Marques, J. M., Bown, N. J., \& Henson, M. (2000). Pro-norm and anti-norm deviance within and between groups. Journal of Personality and Social Psychology, 78, 906-912.

Abrams, D., Marques, J. M., Randsley de Moura, G., Hutchison, P., \& Bown, N. J. (2004). The maintenance of entitativity: A subjective group dynamics approach. In V. Yzerbyt, C. M. Judd, \& O. Corneille (Eds.), The psychology of group perception: Perceived variability, entitativity, and essentialism (pp. 361-380). New York: Psychology Press.

Abrams, D., Randsley de Moura, G., Hutchison, P., \& Viki, G. T. (2005). When bad becomes good (and vice versa): Why social exclusion is not based on difference. In D. Abrams, M. A. Hogg, \& J. M. Marques (Eds.), The social psychology of inclusion and exclusion (pp. 161-190). New York: Psychology Press.

Abrams, D., \& Rutland, A. (2008). The development of subjective group dynamics. In S. R. Levy \& M. Killan (Eds.), Intergroup attitudes and relations relation in childhood through adulthood. Oxford, England: Oxford University Press.

Abrams, D., Rutland, A., \& Cameron, L. (2003). The development of subjective group dynamics: Children's judgments of normative and deviant in-group and out-group individuals. Child Development, 74, $1840-1856$

Abrams, D., Rutland, A., Cameron, L., \& Ferrell, J. (2007). Older but wilier: Ingroup accountability and the development of subjective group dynamics. Developmental Psychology, 43, 134-148.

Abrams, D., Rutland, A., Ferrell, J. \& Pelletier, J. (2008). Children's judgments of disloyal and immoral peer behaviour: Subjective group dynamics in minimal intergroup contexts. Child Development, 79, 444 461 .

Adarves-Yorno, I., Postmes, T., \& Haslam, S. A. (2007). Creative innovation or crazy irrelevance? The contribution of group norms and social identity to creative behavior. Journal of Experimental Social Psychology, 43, 410-416.

Biernat, M., Vescio, T. K., \& Billings, L. S. (1999). Black sheep and expectancy violation: Integrating two models of social judgment. European Journal of Social Psychology, 29, 523-542.

Bown, N. J., \& Abrams, D. (2003). Despicability in the workplace: Effects of behavioral deviance and unlikability on the evaluation in-group and out-group members. Journal of Applied Social Psychology, 33, 2413 2426.

Bray, R. M., Johnson, D., \& Chilstrom, J. T. (1982). Social influence by group members with minority opinions: A comparison of Hollander and Moscovici. Journal of Personality and Social Psychology, 43, 78-88.

Coser, L. A. (1962). Some functions of deviant behavior and normative flexibility. American Journal of Sociology, 68, 172-181.

Eagly, A. H., Karau, S. J., \& Makhijani, M. G. (1995). Gender and the effectiveness of leaders: A meta-analysis. Psychological Bulletin, 117, $125-145$.

Eagly, A. H., Makhijani, M., \& Klonsky, B. (1992). Gender and the evaluation of leaders: A meta-analysis. Psychological Bulletin, 111, 3-22.

Fielding, K. S., \& Hogg, M. A. (1997). Social identity, self-categorization and leadership: A field study of small interactive groups. Group Dynamics: Theory, Research, and Practice, 1, 39-51.

Fiske, S. T. (1993). Social cognition and social perception. Annual Review of Psychology, 44, 155-194. 
Giddens, A. (2000). The third way and its critics. London: Polity Press. Gilbert, D. T., \& Malone, P. S. (1995). The correspondence bias. Psychological Bulletin, 117, 21-38.

Hains, S. C., Hogg, M. A., \& Duck, J. M. (1997). Self-categorization and leadership: Effects of group prototypicality and leader stereotypicality. Personality and Social Psychology Bulletin, 23, 1087-1100.

Haslam, S. A. (2001). Psychology in organizations: The social identity approach. London: Sage.

Haslam, S. A., Oakes, P. J., McGarty, C., Turner, J. C., \& Onorato, R. S. (1995). Contextual changes in prototypicality or extreme and moderate outgroup members. European Journal of Social Psychology, 25, 509530

Haslam, S. A., \& Platow, M. J. (2001). The link between leadership and followership: How affirming social identity translates vision into action. Personality and Social Psychology Bulletin, 27, 1469-1479.

Haslam, S. A., Platow, M. J., Turner, J. C., Reynolds, K. J., McGarty, C., Oakes, P. J., et al. (2001). Social identity and the romance of leadership: The importance of being seen to be "doing it for us." Group Processes and Intergroup Relations, 4, 191-205.

Hogg, M. A. (2001a). Social categorization, depersonalization, and group behavior. In M. A. Hogg \& R. S. Tindale (Eds.), Blackwell handbook of social psychology: Group processes (pp. 56-85). Oxford, England: Blackwell.

Hogg, M. A. (2001b). Social identification, group prototypicality, and emergent leadership. In M. A. Hogg \& D. J. Terry (Eds.), Social identity processes in organizational contexts (pp. 197-212). Philadelphia: Psychology Press.

Hogg, M. A. (2001c). A social identity theory of leadership. Personality and Social Psychology Review, 5, 184-200.

Hogg, M. A. (2005). The social identity perspective. In S. A. Wheelan (Ed.), The handbook of group research and practice (pp. 133-158). London: Sage.

Hogg, M. A., Hains, S. C., \& Mason, I. (1998). Identification and leadership in small groups: Salience, frame of reference, and leader stereotypicality effects on leader evaluations. Journal of Personality and Social Psychology, 75, 1248-1263.

Hogg, M. A., \& van Knippenberg, D. (2003). Social identity and leadership processes in groups. In M. P. Zanna (Ed.), Advances in experimental social psychology (Vol. 35, pp. 2-55). London: Academic Press.

Hollander, E. P. (1958). Conformity, status and idiosyncrasy credit. Psychological Review, 65, 117-127.

Hollander, E. P., \& Julian, J. W. (1970). Studies in leader legitimacy, influence and innovation. In L. Berkowitz (Ed.), Advances in experimental social psychology (Vol. 2, pp. 485-537). New York: Random House.

Homans, G. C. (1974). Social behavior: Its elementary forms. New York: Harcourt.

Levine, J. M. (1989). Reactions to opinion deviance. In B. P. Paulus (Ed.), Psychology of group influence (pp. 187-231). Hillsdale, NJ: Erlbaum.

Levine, J. M., \& Moreland, R. L. (1994). Group socialization: Theory and research. In W. Stroebe \& M. Hewstone (Eds.), European review of social psychology (Vol. 5, pp. 305-336). New York: Wiley

Levine, J. M., \& Moreland, R. L. (2002). Group reactions to loyalty and deviance. Group Cohesion, Trust and Solidarity, 19, 203-228.

Levine, J. M., Moreland, R. L., \& Choi, H.-S. (2001). Group socialization and newcomer innovation. In M. A. Hogg \& R. S. Tindale (Eds.), Blackwell handbook of social psychology: Group processes (pp. 86106). Oxford, England: Blackwell.

Levine, J. M., Moreland, R. L., \& Hausmann, L. R. M. (2005). Managing group composition: Inclusive and exclusive role transitions. In D. Abrams, M. A. Hogg, \& J. M. Marques (Eds.), The social psychology of inclusion and exclusion (pp. 137-160). New York: Psychology Press.

Lord, R. (1977). Functional leadership behaviour: Measurement and rela- tion to social power and leadership perceptions. Administrative Science Quarterly, 22, 114-133.

Lord, R., \& Hall, R. (2003). Identity, leadership categorization, and leadership schema. In D. van Knippenberg \& M. A. Hogg (Eds.), Leadership and power: Identity processes in groups and organizations (pp. 48-64). Oxford, England: Blackwell.

Lord, R. G., \& Maher, K. J. (1990). Perceptions of leadership and their implications in organizations. In J. S. Carroll (Ed.), Applied social psychology and organizational settings (pp. 129-154). Hillsdale, NJ: Erlbaum.

Major, J. (2000). John Major: The autobiography. London: HarperCollins.

Marques, J. M., Abrams, D., Páez, D., \& Taboada, C. M. (1998). The role of categorization and ingroup norms in judgments of groups and their members. Journal of Personality and Social Psychology, 75, 976-988.

Marques, J. M., Abrams, D., \& Serodio, R. G. (2001). Being better by being right: Subjective group dynamics and derogation of ingroup deviants when generic norms are undermined. Journal of Personality and Social Psychology, 81, 436-447.

Marques, J. M., \& Páez, D. (1994). The "black sheep effect:" Social categorization, rejection of ingroup deviates, and perception of group variability. In W. Stroebe \& M. Hewstone (Eds.), European Review of Social Psychology (Vol. 5, pp. 38-68). Chichester, England: Wiley \& Sons.

Marques, J. M., Páez, D., \& Abrams, D. (1998). Social identity and intragroup differentiation as subjective social control. In S. Worchel, J. F. Morales, D. Páez, \& J.-C. Deschamps (Eds.), Social identity: International perspectives (pp. 124-141). New York: Sage.

Marques, J. M., Yzerbyt, V. Y., \& Leyens, J.-Ph. (1988). The "black sheep effect:" Extremity of judgments towards ingroup members as a function of ingroup identification. European Journal of Social Psychology, 18, $1-16$.

Morris, L., Hulbert, L. G., \& Abrams, D. (2000). An experimental investigation of group member influence over leader decisions. Group Dynamics, 4, 157-167.

Morton, T. A., Postmes, T., \& Jetten, J. (2007). Playing the game: When group success is more important than downgrading deviants. European Journal of Social Psychology, 37, 599-616.

Park, B., \& Rothbart, M. (1982). Perception of outgroup homogeneity and levels of social categorization: Memory for subordinate attributes of ingroup and outgroup members. Journal of Personality and Social Psychology, 42, 1051-1068.

Platow, M. J., \& van Knippenberg, D. (2001). A social identity analysis of leadership endorsement: The effects of leader ingroup prototypicality and distributive intergroup fairness. Personality and Social Psychology Bulletin, 27, 1508-1519.

Platow, M. J., van Knippenberg, D., Haslam, S. A., van Knippenberg, B., \& Spears, R. (2006). A special gift we bestow on you for being representative of us: Considering leader charisma from a selfcategorization perspective. British Journal of Social Psychology, 45, 303-320.

Prentice, D. A., \& Miller, D. T. (1993). Pluralistic ignorance and alcohol use on campus: Some consequences of misperceiving the social norm. Journal of Personality and Social Psychology, 64, 243-256.

Randsley de Moura, G., \& Abrams, D. (2002, June). Does leadership role alone enhance trust in a non-prototypical group member? Paper presented at the 13th general meeting of the European Association of Experimental Social Psychology, San Sebastian, Spain.

Reicher, S., Haslam, S. A., \& Hopkins, N. (2005). Social identity and the dynamics of leadership: Leaders and followers as collaborative agents in the transformation of social reality. The Leadership Quarterly, 16, $547-568$.

Reicher, S., \& Hopkins, N. (2003). On the science and art of leadership. In D. van Knippenberg \& M. A. Hogg (Eds.), Leadership and power: 
Identity processes in groups and organizations (pp. 197-209). Oxford, England: Blackwell.

Ross, L. (1977). The intuitive psychologist and his shortcomings. In L. Berkowitz (Ed.), Advances in experimental social psychology (Vol. 10, pp. 173-220). San Diego, CA: Academic Press.

Stephenson, G. M. (1991). Intergroup bargaining and negotiation. In J. C. Turner \& H. Giles (Eds.), Intergroup behavior (pp. 168-198). Oxford, England: Blackwell.

Tajfel, H., \& Turner, J. (1979). An integrative theory of intergroup conflict. In W. G. Austin \& S. Worchel (Eds.), The social psychology of intergroup relations (pp. 33-47). Monterey, CA: Brooks-Cole.

Turner, J. C. (1991). Social influence. Buckingham, England: Open University Press.

Turner, J. C., \& Haslam, S. A. (2001). Social identity, organizations, and leadership. In M. E. Turner (Ed.), Groups at work: Advances in theory and research (pp. 25-65). Hillsdale, NJ: Erlbaum.

Turner, J. C., Hogg, M. A., Oakes, P. J., Reicher, S. D., \& Wetherell, M. S.
(1987). Rediscovering the social group: A self-categorisation theory. London: Blackwell.

van Knippenberg, D., \& van Knippenberg, B. (2005). Leader self-sacrifice and leadership effectiveness: The moderating role of leader prototypicality. Journal of Applied Psychology, 90, 25-37.

Xiang, N., \& Masser, B. M. (2006). Appointed and emergent deviant leaders: Does it make a difference? Unpublished manuscript, University of Queensland, Australia

Yukl, G. A. (2002). Leadership in organisations (3rd ed.). Englewood Cliffs, NJ: Prentice Hall.

Zdaniuk, B., \& Levine, J. M. (2001). Group loyalty: Impact of members' identification and contributions. Journal of Experimental Social Psychology, 37, 502-509.

Received July 17, 2007

Revision received December 12, 2007

Accepted December 13, 2008

\section{American Psychological Association SubSCRIPTION Claims Information}

Today's Date:

We provide this form to assist members, institutions, and nonmember individuals with any subscription problems. With the appropriate information we can begin a resolution. If you use the services of an agent, please do NOT duplicate claims through them and directly to us. PLEASE PRINT CLEARLY AND IN INK IF POSSIBLE.

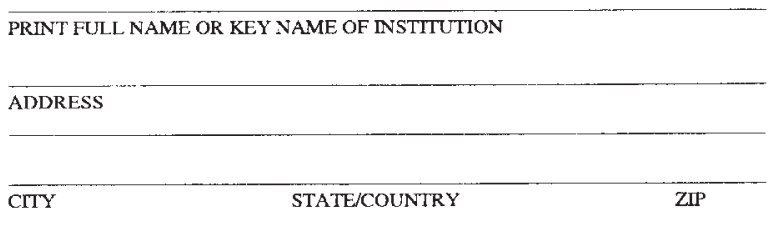

YOUR NAME AND PHONE NUMBER

TITLE

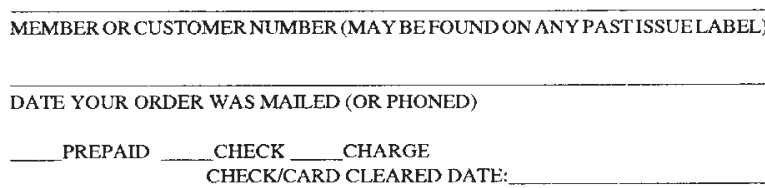

(If possible, send a copy, front and back, of your cancelled check to help us in our research of your claina.)

ISSUES: ___ MISSLNG DAMAGED

Thank you. Once a claim is received and resolved, delivery of replacement issues routinely takes 4-6 weeks.

DATE RECEIVED ACTION TAKEN:

STAFF NAME:
(TO BE FILLED OUT BY APA STAFF)

DATE OF ACTION:

INV. NO. \& DATE:

LABEL NO. \& DATE:

Send this form to APA Subscription Claims, 750 First Street, NE, Washington, DC 20002-4242

PLEASE DO NOT REMOVE. A PHOTOCOPY MAY BE USED. 